\title{
Market Prices of Risk with Diverse Beliefs, Learning, and Catastrophes
}

\author{
By Timothy Cogley, Thomas J. Sargent and Viktor Tsyrennikov*
}

We compare market prices of risk in economies with identical patterns of endowments, priors, and information flows, but two different market structures, one with complete markets, another in which consumers can trade only a single risk-free bond. We study how opportunities to speculate, uncommon priors, and learning affect market prices of risk. Two types of consumers have diverse beliefs about the law of motion for a random exogenous endowment. One type knows the true law of motion while the other type learns about it via Bayes's theorem. Less-well-informed consumers are pessimistic, initially overestimating the probability of a catastrophic state. Learning dynamics and the wealth dynamics that they drive contribute to differences in evolutions of market prices of risk across market structures. ${ }^{1,2}$

\section{The endowment process}

Two types of consumers receive equal shares of a non-storable aggregate endowment $y\left(g^{t}\right), y^{i}\left(g^{t}\right)=y\left(g^{t}\right) / 2, i=1,2$. Growth in the aggregate endowment $g_{t}$ takes on one of three values $\left\{g_{h}, g_{m}, g_{l}\right\} \equiv$ $\mathcal{G}$. A history of realizations through date $t$ is denoted $g^{t}$. Growth outcomes depend on the realization of two independent random variables, $s$ and $d$. The random variable $s$ is Markov with transition matrix $\Pi_{s}$. The

* Cogley: NYU, email: tim.cogley@nyu.edu; Thomas J. Sargent: NYU and Hoover Institution, email: thomas.sargent@nyu.edu; Viktor Tsyrennikov: Cornell University. Email: vt68@cornell.edu.

${ }^{1}$ Blume and Easley (2006) examine who survives in the long run in such economies, and Cogley, Sargent, and Tsyrennikov (2011) study transitional wealth dynamics.

${ }^{2} \mathrm{~A}$ number of abbreviations are used throughout the paper. $R E$ stands for 'rational expectations', MPR is 'market price of risk', IMRS denotes 'intertemporal marginal rate of substitution', and SDF is 'stochastic discount factor'. random variable $d$ is an iid Bernoulli variate with success probability $p_{d}$. The mapping from $(s, d)$ realizations to $g_{t}$ is $g=g_{h}$ when $s=1$ and $d=1$ or $d=2, g=g_{m}$ when $s=2$ and $d=1$, and $g=g_{d}$ when $s=2$ and $d=2$.

The time period is one year. The highgrowth state $g_{h}=1.03$ represents an expansion, the medium-growth state $g_{m}=0.99$ is a mild recession, and the low-growth state $g_{l}=0.9$ is a deep contraction. Probabilities are calibrated so that an expansion has a median duration of 8 years $\left(p_{11}^{s}=0.917\right)$, a mild recession has a median duration of 1 year $\left(p_{22}^{s}=0.50\right)$, and 1 in 10 contractions is deep $\left(p_{d}=0.10\right)$. The implied transition matrix for $g_{t}$ is

$$
\text { (1) } \Pi_{g}=\left[\begin{array}{rrr}
0.917 & 0.0747 & 0.0083 \\
0.50 & 0.45 & 0.05 \\
0.50 & 0.45 & 0.05
\end{array}\right] \text {, }
$$

and the invariant probabilities are $[0.858,0.128,0.014]$. The unconditional probability of a deep contraction is similar to estimates in Barro (2006).

\section{Information and beliefs}

Both types of consumers observe realizations of $g_{t}$ but not realizations of $\left(s_{t}, d_{t}\right)$. For simplicity, we assume that both consumers know $\Pi_{s}$ and that $p_{d}$ is known only to the type 2 consumer. Type- 1 consumers learn about $p_{d}$ by applying Bayes's theorem. They have identical beta priors on $p_{d}$, $f\left(p_{d}\right)=\mathcal{B}\left(n_{0}, m_{0}\right)$, where $n_{0}$ and $m_{0}$ are the prior numbers of deep and mild contractions, respectively. To represent initial pessimism, we set $n_{0}=m_{0}=5$, implying a prior mean $\hat{p}_{d 0}=0.5$. The implied prior 
transition and long-run probabilities are

$$
\Pi_{g 0}^{1}=\left[\begin{array}{rrr}
0.917 & 0.0415 & 0.0415 \\
0.50 & 0.25 & 0.25 \\
0.50 & 0.25 & 0.25
\end{array}\right],
$$

and $[0.858,0.071,0.071]$, respectively. The less informed type 1 consumers therefore initially overestimate the likelihood of deep contractions and underestimate that of mild recessions.

Because $d$ is an iid Bernoulli random variable, the posterior is also a beta density, $f\left(p_{d} \mid g^{t}\right)=\mathcal{B}\left(n_{0}+n_{t}, m_{0}+m_{t}\right)$, where $n_{t}$ and $m_{t}$ are the observed numbers of deep and mild contractions, respectively, counted through date $t$. Type 1 consumers form one-step ahead expectations using a subjective transition matrix of the same form as the true transition matrix but with the posterior mean $\hat{p}_{d t}$ replacing $p_{d}$. Betterinformed type- 2 consumers form expectations using the true transition matrix (1).

We study what Grossman (1981) calls Walrasian equilibria in which traders infer no information from prices.

\section{Preferences}

Consumers rank consumption plans using the welfare function,

$$
U^{i}(c)=E^{i} \sum_{t=0}^{\infty} \beta^{t} \frac{c_{i}\left(g^{t}\right)^{1-\gamma}}{1-\gamma},
$$

where $E^{i}$ denotes a mathematical expectation taken with respect to consumer $i$ 's subjective distribution. The parameters $\beta=1.04^{-1}$ and $\gamma=2$ are the same across types, but expectations are formed differently, with each consumer averaging future outcomes using his own subjective probability distribution. Consumers choose consumption, savings, and portfolio plans to maximize expected utility subject to their flow budget constraints and debt limits.

\section{Asset markets and constraints}

We study two market structures: complete markets and an economy in which consumers can trade only a risk-free one-period bond. In the complete-market model, a full set of Arrow securities is traded. In this case, consumer $i$ 's flow budget constraint is

$$
\begin{array}{r}
y^{i}\left(g^{t}\right)+a^{i}\left(g_{k} \mid g^{t-1}\right) \geqslant c^{i}\left(g^{t}\right) \\
+\sum_{j \in \mathcal{G}} Q\left(g_{j} \mid g^{t}\right) a^{i}\left(g_{j} \mid g^{t}\right),
\end{array}
$$

where $Q\left(g_{j} \mid g^{t}\right)$ and $a^{i}\left(g_{j} \mid g^{t}\right)$ denote the price and quantity purchased at history $g^{t}$ of the Arrow security paying off when $g_{t+1}=g_{j}$. Individuals can borrow by taking negative positions in Arrow securities subject to natural borrowing limits that constrain total borrowing to be no greater than the maximum that can be repaid with certainty.

When the only traded security is a riskfree bond, the flow-budget constraint is

$$
y^{i}\left(g^{t}\right)+b^{i}\left(g^{t-1}\right) \geqslant c^{i}\left(g^{t}\right)+q_{b}\left(g^{t}\right) b^{i}\left(g^{t}\right),
$$

where $q_{b}\left(g^{t}\right)$ and $b^{i}\left(g^{t}\right)$ represent the price of the bond and the quantity held by consumer $i$, respectively. Individuals can borrow by taking a negative position in the bond subject to an exogenous borrowing limit, which we assume is twice a consumer's annual income.

Market prices of risk from various perspectives

Gross returns of traded securities satisfy subjective Euler equations,

$$
E_{t}^{i}\left(M_{t+1}^{i} R_{j t+1}\right)=1,
$$

where $M_{t+1}^{i}=\beta\left(c_{i t+1} / c_{i t}\right)^{-\gamma}$ represents consumer $i$ 's IMRS, $R_{j t}$ is the gross return on security $j$, and $E_{i t}$ is the conditional expectation taken with respect to consumer $i$ 's posterior predictive density. Subjective market prices of risk are defined as

$$
\operatorname{MPR}^{i}\left(g^{t+1}\right)=\frac{\sigma_{t}^{i}\left(M^{i}\left(g^{t+1}\right)\right)}{\mu_{t}^{i}\left(M^{i}\left(g^{t+1}\right)\right)},
$$

where $\mu_{t}^{i}$ and $\sigma_{t}^{i}$ denote the conditional mean and standard deviation, respectively, computed using consumer $i$ 's beliefs.

We also define a rational-expectations Euler equation

$$
E_{t}\left(M_{t+1}^{r e} R_{j t+1}\right)=1
$$


where expectations are taken with respect to probabilities of the actual data generating mechanism. Since consumer 2's beliefs are correct, his IMRS is one valid $R E$ pricing kernel, $M_{t+1}^{2, r e}=M_{t+1}^{2}$. However, because consumer 1 's beliefs temporarily differ from actual probabilities, his IMRS is not a valid $R E$-pricing kernel. A valid pricing kernel involving consumer 1's IMRS can be found by introducing a change of measure in (2),

$$
\sum_{g_{k} \in \mathcal{G}} M^{1, r e}\left(g^{t+1}\right) R_{j}\left(g_{k} \mid g^{t}\right) \pi^{2}\left(g_{k} \mid g^{t}\right)=1,
$$

where

(5) $M^{1, r e}\left(g^{t+1}\right)=M^{1}\left(g_{t+1} \mid g^{t}\right) \frac{\pi^{1}\left(g_{t+1} \mid g^{t}\right)}{\pi^{2}\left(g_{t+1} \mid g^{t}\right)}$

is a second valid $R E$-pricing kernel. $R E$ MPRs are defined as

$$
\operatorname{MPR}^{i, r e}\left(g^{t+1}\right)=\frac{\sigma_{t}\left(M^{i, r e}\left(g^{t+1}\right)\right)}{\mu_{t}\left(M^{i, r e}\left(g^{t+1}\right)\right)},
$$

where $\mu_{t}$ and $\sigma_{t}$ denote the conditional mean and standard deviation, respectively, computed using the actual law of motion for $g_{t}$ and $M^{i, r e}\left(g^{t+1}\right)$ refers either (5) or $M_{t+1}^{2}$.

When markets are complete, a unique $R E$-pricing kernel exists, and $R E$-prices of risk are equated across consumers. Because consumer 2 has correct beliefs, the unique $R E$-price of risk also coincides with his subjective MPR. The subjective MPR for consumer 1 can differ, however, because he uses a different probability distribution to evaluate the conditional moments in (3). When markets are incomplete, not only can subjective MPRs differ across consumers, so can $R E$ MPRs.

\section{Simulation results}

As a point of departure, we temporarily assume that the economy is populated entirely by well-informed type 2 consumers. Prices and allocations are therefore determined as in a conventional rationalexpectations equilibrium. For this benchmark, the conditional MPRs are 0.035 in the expansion state and 0.068 in both of the contraction states, and the unconditional MPR is 0.044. Thus, despite the presence of a catastrophe state, the MPRs fall short of Hansen and Jagannathan's (1991) lower bound of 0.25 . We can increase the MPR by making consumers more risk averse, deepening the catastrophe state, or making the catastrophe state more probable, but we prefer another route, namely introducing heterogeneous beliefs and learning.

Figure 1 portrays unconditional MPRs for a pair of diverse-beliefs economies, with panel (a) depicting outcomes under complete markets and panel (b) illustrating those for the bond-only economy. ${ }^{3}$ In panel (a), the dashed line represents consumer 2's subjective MPR and is also the unique $R E$ MPR for both consumers. The solid line is consumer 1's subjective MPR. Both are substantially larger than under rational expectations. Consumer 2's MPR exceeds the Hansen-Jagannathan bound at the beginning of the transition but declines quickly and falls short of the bound after a few years.

Consumer 2's MPR is higher than under RE because he accepts financial risks that increase his consumption volatility. Since type- 1 consumers are pessimistic, Arrow securities paying off in the catastrophe state are overpriced relative to rationalexpectations valuations and those paying off in mild recessions are underpriced. The better-informed type 2 consumers regard these price gaps as attractive trading opportunities, and therefore they sell over-priced deep-contraction securities and buy under-priced mild-recession securities. They grow rich on average because deep contractions occur less often than the less informed type-1 consumers expect. But when a deep contraction does occur, type-2 consumers suffer a decline in their endowment and must also pay off on their financial liabilities. Their financial positions increase exposure to catastrophic risk, boosting their MPRs.

Consumer 1's subjective MPR is higher for two reasons: because his bets on Ar-

\footnotetext{
${ }^{3}$ These were computed by averaging across 50,000 sample paths for $g_{t}$, each of length 200 years.
} 
a) MPR: complete markets

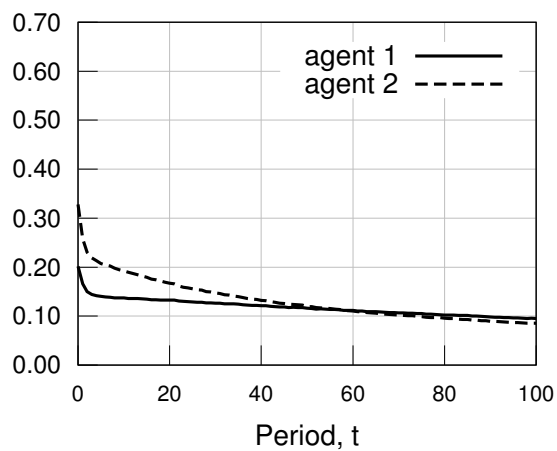

c) $\operatorname{std}_{t}\left(c_{t+1}^{i}\right)$ : complete markets

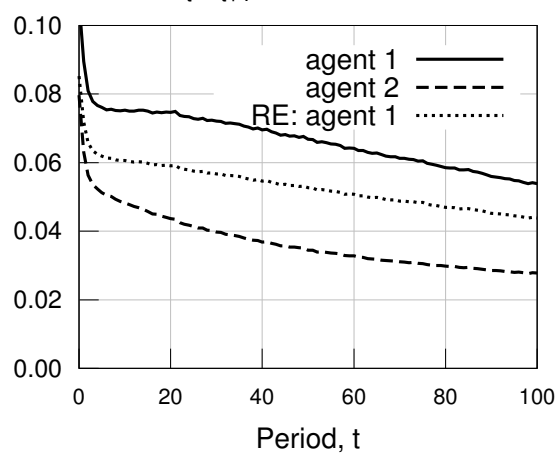

b) MPR: bond economy

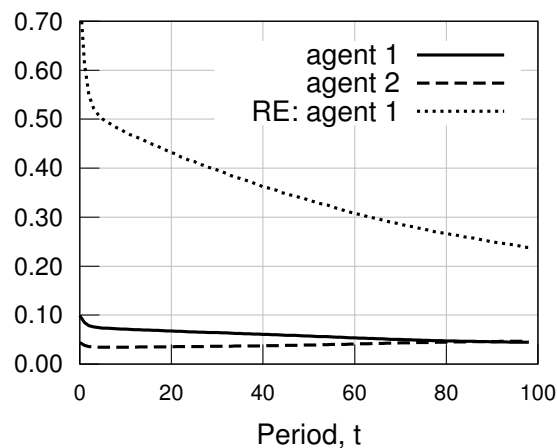

d) $\operatorname{std}_{t}\left(c_{t+1}^{i}\right)$ : bond economy

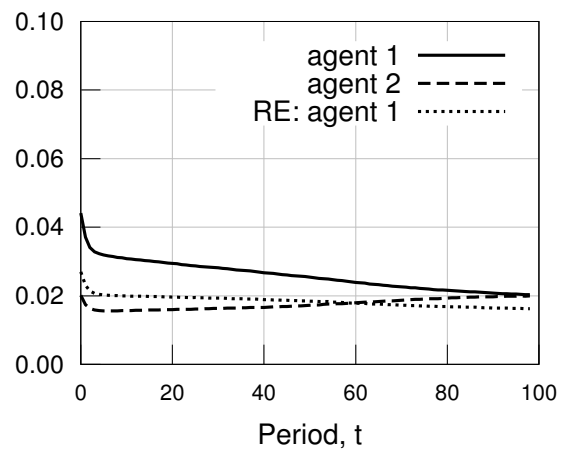

Figure 1. UnCONDITIONAL MARKET PRICES OF RISK AND PERCEIVED AND ACTUAL CONSUMPTION GROWTH VOLATILITY

row securities increase actual consumptiongrowth volatility and because he believes that his consumption growth is more volatile than it actually is (cf. panel c). Both consumers willingly accept more volatile consumption plans because both expect to earn substantial returns.

Panel (b) portrays unconditional MPRs in the bond economy. The solid and dashed lines again represent subjective MPRs for consumers 1 and 2 , and the dotted line represents consumer 1's RE MPR. Because consumers cannot trade state-contingent securities, the direction in which wealth is transferred is reversed, with type- 1 consumers accumulating financial assets and type- 2 consumers being driven to debt limits. When markets are complete, type-1 consumers guard against deep contractions by purchasing an Arrow security that pays off in that state. In the bond economy, they self-insure against deep contractions by accumulating risk-free bonds. The riskfree real-interest rate adjusts so that better- informed consumers are content to sell riskfree bonds. Since no side bets are made on state-contingent securities, consumption shares remain close to income shares, and consumption-growth volatility is reduced, damping subjective MPRs. Indeed, subjective MPRs are now only slightly higher than under rational expectations.

Although the less informed consumer 1's consumption growth is less volatile than under complete markets, his $R E$ MPR is much higher, exceeding the Hansen-Jagannathan bound for almost 100 years. ${ }^{4}$ The difference between his IMRS volatility and his $R E$ MPR is due to the volatility of the probability ratio $r\left(g^{t+1}\right)=\pi^{1}\left(g_{t+1} \mid g^{t}\right) / \pi^{2}\left(g_{t+1} \mid g^{t}\right)$ displayed in equation 5 . His $R E$ price of risk is high not because consumption growth is volatile, but because this probability ratio is volatile. We can decompose

\footnotetext{
${ }^{4}$ Consumer 2's IMRS ceases to be a valid RE pricing kernel after he is driven to his debt limit. This occurs around year 80 .
} 
a) $\operatorname{var}_{t}\left(M_{t+1}^{1} r_{t+1}\right)$

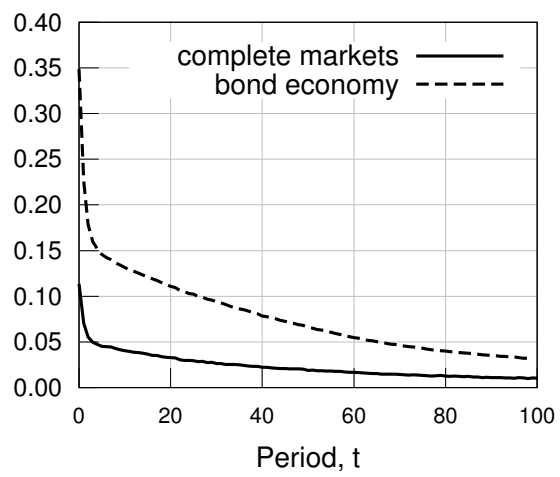

b) $\operatorname{cov}_{t}\left[\left(M_{t+1}^{1}\right)^{2},\left(r_{t+1}\right)^{2}\right]$

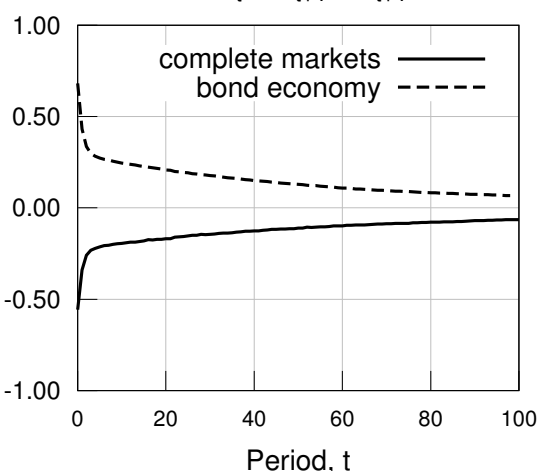

Figure 2. Components of the variance of $M^{1, r e}$

the variance of consumer 1's $R E \mathrm{SDF}$ as

$$
\begin{aligned}
& \operatorname{var}_{t}\left(M_{t+1}^{1} \cdot r_{t+1}\right)=E_{t}\left[\left(M_{t+1}^{1}\right)^{2}\right] E_{t}\left[\left(r_{t+1}\right)^{2}\right] \\
& +\operatorname{cov}_{t}\left[\left(M_{t+1}^{1}\right)^{2},\left(r_{t+1}\right)^{2}\right]-\left(E_{t}\left[M_{t+1}^{1} r_{t+1}\right]\right)^{2}
\end{aligned}
$$

The term $E_{t}\left[r_{t+1}^{2}\right]$ is large but its effect can be overcome by the covariance term $\operatorname{cov}_{t}\left[\left(M_{t+1}^{1}\right)^{2},\left(r_{t+1}\right)^{2}\right]$. Because financial markets are incomplete, consumption of agent 1 responds positively to changes in income. Thus, the covariance term is positive, and the high volatility of the probability ratio translates into high volatility of the $R E$ stochastic discount factor. This is not true under complete markets: consumption reacts strongly to changes in the probability ratio. For example, consumer 1 underestimates probability of a mild recession state and sells Arrow securities paying in this state. So, when a mild recession does occur his consumption decreases and the IMRS increases, leading to a negative correlation between consumer 1's IMRS and the probability ratio. Panel (a) in figure 2 depicts the variance of consumer 1's $R E \mathrm{SDF}$ under the two market structures. Panel (b) shows that $\operatorname{cov}_{t}\left(M^{1, r e}, r\right)$ is positive in the bond economy, leading to a higher $R E$ price of risk.

\section{Conclusions}

Speculation and market incompleteness both contribute to high MPRs. When opportunities to speculate are abundant because markets are complete, survival dy- namics amplify the volatility of individual consumption growth. Subjective MPRs are high, but not as high as a lower bound on the $R E \mathrm{MPR}$. The $R E \mathrm{MPR}$ is even higher and initially exceeds that lower bound, but it declines quickly as the less informed type 1 consumers learn. In the bond economy, opportunities to speculate are nearly absent and subjective MPRs are low. Nevertheless, a wedge that measures belief differentials makes the $R E$ MPR be very high and well above the lower bound.

\section{References}

Barro, R.J., 2006, Rare Disasters and Asset Markets in the Twentieth Centure, Quarterly Journal of Economics 121, 823866.

Blume, L. and D. Easley, 2006, If You'Re So Smart, Why Aren't You Rich? Belief Selection In Complete And Incomplete Markets, Econometrica 74(4), 929-966.

Cogley, T., T.J. Sargent, and V. Tsyrennikov, 2011, Wealth dynamics in a bond economy with heterogeneous agents, unpublished manuscript.

Grossman, S. J, 1981, An Introduction to the Theory of Rational Expectations under Asymmetric Information, Review of Economic Studies, 48(4), 541-59.

Hansen, L.P. and R. Jagannathan, 1991, Implications of security market data for models of dynamic economies, Journal of Political Economy 91, 225-262. 